\title{
Order of embryonic determination of the differential features of gamic and parthenogenetic aphids ${ }^{1}$
}

\author{
By A. Franklin Shull \\ (University of Michigan, Ann Arbor, Mich., U. S. A.)
}

(With 1 Textfig.)

(Received June 11, 1930)

\begin{abstract}
When, in a species of organism, there exist two forms of individual built on the same general plan but differing in detail with respect to recognizably homologous parts, important information regarding the time of determination of the differential parts can be gained, provided each of these forms can be converted, by stages, into the other. So far, attempts to gain this information have dealt almost exclusively with contrasts between the two sexes. A somewhat simpler contrast, because less extreme differences are involved, is that afforded by the gamic and parthenogenetic females in aphids. It has been shown (Shull, 1930) that in the species Macrosiphum solanifolii this reciprocal conversion may be effected by temperature. The gamic females were found to be produced by winged mothers at low temperature, while. similar parents at high temperature produced parthenogenetic females. Winged females kept early in life at low temperature, then removed to high temperature, produced mostly gamic daughters at first, then changed gradually to the production of parthenogenetic daughters. Furthermore, when the offspring of such parents had been changed from gamic to parthenogenetic while a considerable portion of the reproductive period of the parents still remained, a return to low temperature was followed by a gradual change toward gamic daughters again. During the period of change, in both directions, many intermediate forms appeared. These showed only slight changes early in the period, but increasingly great differences thereafter until the transformation was complete.
\end{abstract}

1 Contribution from the Zoological Laboratory of the University of Michigan. 


\section{Differences between gamic and parthenogenetic females}

Gamic females of this species of aphid have a wax-yellow body color, dark brown antennae, and greatly swollen hind tibiae of dark brown color, covered with hundreds of sensoria. Their reproductive systems consist of a vagina on which are borne a pair of colleterial glands and a seminal receptacle, a pair of short oviducts formed as branches of the

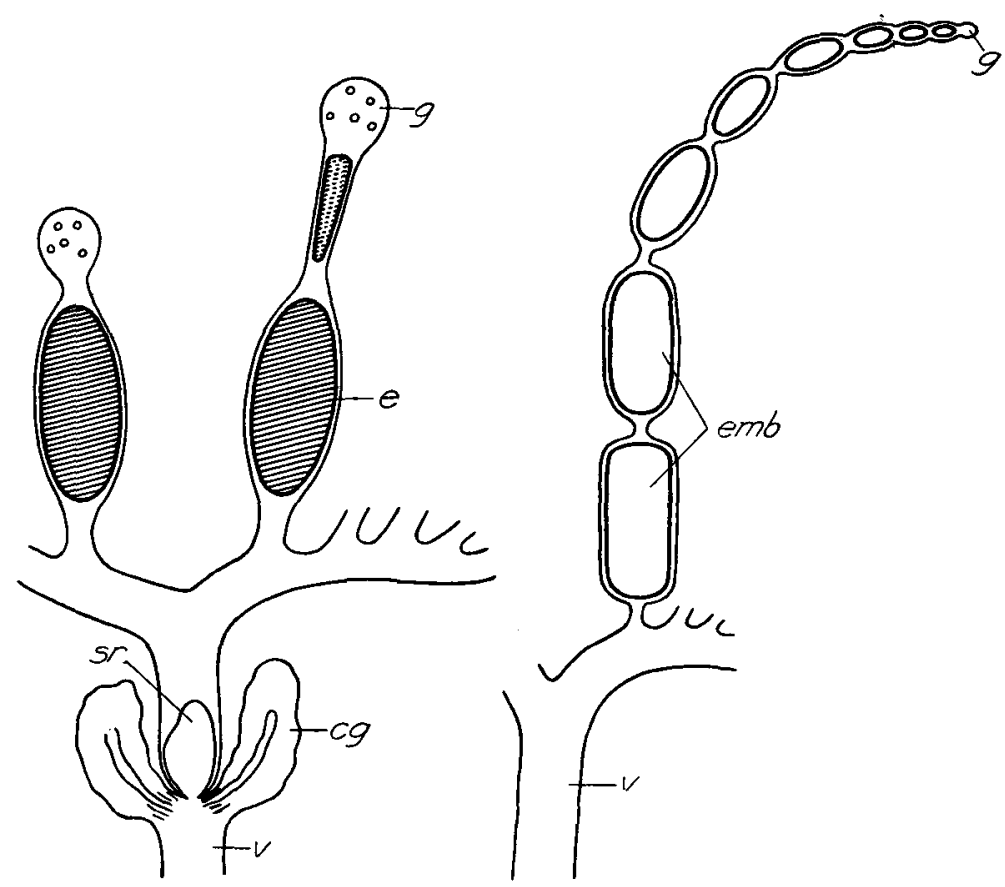

Fig. 1. Diagrams of reproductive systems of aphids, gamic at left, parthenogenetic at right. eg, colleterial gland; e, egg; emb, embryo; g, germarium; sr, seminal receptacle; $\mathbf{v}$, vagina

vagina, and a variable number (usually ten) of ovarioles branching from the oviducts (Fig. 1). Each ovariole, in a mature female, contains usually one mature or nearly mature egg, distinctly opaque and of very regular ovoid form; beyond this often an oöcyte, in early growth stage, hence long and slender and not very opaque; and lastly a large, spherical germarium forming a conspicuous knob at the end of the ovariole. In old gamic females, especially those that have not been laying eggs, the second reproductive cell from the base of the ovariole may be large and opaque 
and regular in form, and is then presumably mature like the one posterior to it. Almost never, however, in typical gamic females (that is, those produced at low temperature by winged females whose other daughters are practically all gamic), are there more than two oöcytes in any stage in one ovariole. An ovariole of a gamic female may therefore be regarded. as regularly consisting of a tube containing one or two eggs or oöcytes, and a large round germarium.

The parthenogenetic females have bright green body color, antennae quite pale except in the distal segment, and very slender, pale hind tibiae bearing no sensoria. The reproductive system consists of a vagina, without colleterial glands or seminal receptacle, two short oviducts branching from the vagina, and a variable number (apparently up to ten) of ovarioles branching from the oviducts. Each ovariole is a very delicate tube containing, in healthy individuals, usually six to nine embryos or eggs or oöcytes, and bearing at the end a very small germarium which is usually not much larger, and is often smaller, than the oöcyte or egg next behind it. All of these reproductive elements except one (the one next to the germarium) are as a rule embryos in some stage of development. They are all translucent or transparent, unless dead, and if dead they have a clouded appearance not at all like the opaque gamic eggs. Only the smaller embryos are ellipsoidal; the medium and larger ones always possess angles which correspond to the form of the young aphids. The six to nine embryos or eggs in one ovariole, in a typical healthy female, are of regularly decreasing size from oviduct to germarium, so that they resemble a tapering string of beads.

\section{Numerical rating of the differential characters}

In order to indicate the degree of intermediacy of the nontypical forms produced during the change from one type of daughter to the other, a range of numerical values was arbitrarily given to the grades of each differentiating character. These values were in general such that 0 represented the extreme found in gamic females, while 4 represented the extreme occurring in parthenogenetic females.

With respect to body color, 0 meant the wax-yellow of the typical gamic female, 1 a greenish yellow, 2 and 3 increasingly green color, and 4 a bright green. A water-color chart representing these colors was prepared, and was kept constantly in view when body colors were being judged. There was enough variation among a large number of typical gamic females (those produced at low temperature, whose sisters were 
practically all gamic) to make their mean color 0.08 ; and enough variation among typical wingless parthenogenetic females (healthy females produced at high temperature, whose sisters were all parthenogenetic) to give them a mean color rating of 3.94 .

The brown color of both antennae and hind tibiae were judged by a single numerical standard. The deepest brown observed in any antenna was about the same as the deepest brown in any tibia, and was rated 0 ; the palest color of antennae (omitting the distal segment) was about the same as the palest color of tibiae, and was rated 4. However, there was considerable variability in the color of both antennae and hind tibiae in typical gamic females, so that the mean antennal color of a large number of these proved to be 1.47, and the mean tibial color 0.54. The rating of typical wingless parthenogenetic females was in each of these characters exactly 4.00 .

The swollen hind tibia of the typical gamic female was rated 0 , the slender tibia of the parthenogenetic female was indicated by 4 . A water color figure, showing not only these sizes but the shades of brown which, on the average, went with the sizes, was kept in view during all judgments of these characters. Here, again, the mean gamic size was not 0 , but 0.26 ; but the mean tibial size of parthenogenetic females was precisely 4.00 .

For convenience of reference, these numerical values, representing the ranges of difference between typical gamic and typical parthenogenetic females, are collected in table 1. Interpretation of the summarized results presented in this article would be facilitated by adjusting the values so that 0 in each case represented the condition of the mean gamic female, 4 the condition of the mean parthenogenetic female. Were that done, however, it would be difficult, in presenting the detailed evidence, to represent those smaller groups of aphids which are more extreme than the mean of their general class. The figures are allowed to stand, therefore, as they were obtained. The reader should be able to make the necessary adjustments without difficulty.

To the table has been added a rating of the reproductive systems, 0 for the gamic, 4 for the parthenogenetic. While many intermediate reproductive systems were found, a much greater number of aphids which were intermediate in one or more of the externally visible characters were definitely gamic or parthenogenetic in the reproductive organs. The intermediate values given in the later tables are in large measure the means of varying numbers of wholly gamic or wholly parthenogenetic individuals. No particular intermediate conditions of the 
Table 1. The numerical values of the differential characters of typical gamic and parthenogenetic aphids, according to the arbitrary scale described in the text

\begin{tabular}{|c|c|c|}
\hline Character & Gamic & $\begin{array}{c}\text { Partheno- } \\
\text { genetic }\end{array}$ \\
\hline Color of antenna. . . & 1.47 & 4.00 \\
\hline Color of body . . . & 0.08 & 3.94 \\
\hline Size of hind tibia . & 0.26 & 4.00 \\
\hline Color of hind tibia . . & 0.54 & 4.00 \\
\hline Reproductive system . & 0.00 & 4.00 \\
\hline
\end{tabular}

reproductive system have been given specific intermediate values between 0 and 4, since it seems advisable to consider these intermediates more particularly in a separate section.

Classification of the aphids with respect to all these characters was done on the living animals, etherized if necessary. Every individual was judged separately for each of the five differential characters. When color was being judged, especially that of antennae and tibiae, the aphids were always placed in the same position in relation to the source of light. Reproduction was judged externally if several opaque, regular eggs or several embryos with their pigmented eyes could be seen through the transparent body wall. If this could not be done, the animal was dissected.

\section{Change from gamic to parthenogenetic}

The change from gamic to parthenogenetic daughters was made, partially or completely, in two general ways, (a) by applying high temperatures to the winged parents for varying periods after their birth and observing the nature of their first offspring after the change, and (b) by permanently changing the winged parents from low to high temperature and observing the progressive change of their successive offspring.

a. High temperalure for varying periods after birth. Numerous wingless females were kept in alternating light and darkness for several days, at room temperatures in winter, after which time their offspring should be chiefly winged, as shown by former work (Shull, 1928). These offspring, within 24 hours after birth, were put in a chamber in which the temperature was $24^{\circ} \mathrm{C}$, and exposed to continuous light. Some were left 3 days at this temperature, some 6 days, and other lots 9,12 , and 16 days, respectively, At the end of the allotted time, they were put at $16^{\circ} \mathrm{C}$ in 
continuous light. Before they reached maturity the few wingless individuals among them were removed, so that offspring were obtained only from winged parents. Those which were kept 3 or 6 days at high temperature had not begun to reproduce when changed to $16^{\circ}$; the first offspring produced by them at maturity were the ones recorded. Those kept 9 days at $24^{\circ}$ were beginning to reproduce when changed to $16^{\circ}$; practically their first offspring were recorded. The females kept 12 or 16 days at $24^{\circ}$ had been reproducing for some days before the change to $16^{\circ}$; these earlier offspring were discarded, and only those produced after the change to $16^{\circ}$ were recorded. In each case, the offspring produced in a 2-day period were examined. Each individual was judged with respect to the five differentiating characters of the gamic and parthenogenetic aphids, in the manner and according to the standards described in the preceding section. Their mean ratings, each based on 19 to 36 individuals, are shown in table 2, to which is added, in the first line, a group of aphids whose winged parents were put at $16^{\circ}$ within 24 hours after birth and were left at that temperature until the end of the experiment. It is the first offspring of these females that serve as controls for the other groups.

Table 2. Showing the change from gamic to parthenogenetic daughters as a result of high temperature, by a comparison of the offspring of different groups of winged parents subjected to high temperature for varying periods after birth. The numerical ratings are those of table 1 .

\begin{tabular}{c|c|c|c|c|c}
\hline $\begin{array}{c}\text { Number of } \\
\text { Days Parents } \\
\text { were at 24. }\end{array}$ & \multicolumn{5}{|c}{$\begin{array}{c}\text { Offspring of First Two Days of Reproduction } \\
\text { After End of } 24^{\circ} \mathrm{C}\end{array}$} \\
\cline { 2 - 6 } & $\begin{array}{c}\text { Color of } \\
\text { antenna }\end{array}$ & $\begin{array}{c}\text { Color of } \\
\text { body }\end{array}$ & $\begin{array}{c}\text { Size of } \\
\text { hind tibiae }\end{array}$ & $\begin{array}{c}\text { Color of } \\
\text { hind tibiae }\end{array}$ & $\begin{array}{c}\text { Reproductive } \\
\text { system }\end{array}$ \\
\hline & & & & & \\
3 & 0.46 & 0.00 & 0.32 & 0.58 & 0.00 \\
6 & 0.35 & 0.00 & 0.50 & 0.55 & 0.00 \\
9 & 1.47 & 0.64 & 0.88 & 0.73 & 0.18 \\
12 & 2.75 & 1.50 & 2.62 & 2.87 & 1.50 \\
16 & 3.67 & 2.40 & 3.93 & 3.80 & 2.53 \\
& 4.00 & 3.56 & 4.00 & 4.00 & 3.63
\end{tabular}

It is apparent that color of antenna and size and color of hind tibia are modified in about equal degree by the various periods of high temperature; but that the effect on body color and the reproductive system is in each case distinctly less. 
b. Continuous high temperature after given stage. Winged aphids which were produced at low temperatures were divided into two equal groups, one of which was kept at $16^{\circ}$, the other removed in (usually) some immature stage to a temperature of $24^{\circ}$. They were reared at their respective temperatures throughout the remainder of their lives. Their offspring were collected in successive lots, each lot at high temperature being usually the output of two days, those at low temperature the output of five days. The experiment was performed several times, from January to March. In each experiment, at high temperature, the offspring were at first strongly gamic, but gradually changed to parthenogenetic. Since the time required for this change was shorter in March than in January, the several experiments must be reported separately, though all are brought together in table $3, \mathrm{p} .99$. The number of offspring obtained in each 2-day or 5-day period ranged from 13 to 46 , the mean being 32.4 .

The parents of these aphids were produced at low temperature, that of slightly underheated laboratories, which was of course irregular, but always low at night at that season (January to March). As was pointed out in a former paper (Shull, 1930), alternating low and moderately high temperature is quite as effective in inducing gamic reproduction as is constant low temperature. It is entirely in accordance with expectation, therefore, that all groups of first offspring in table 3 are almost typical gamic females. At a temperature of $16^{\circ}$, the succeeding offspring are likewise nearly all fairly typical gamic females. At $24^{\circ}$, on the contrary, a change to the parthenogenetic type soon sets in. The beginning of this change occurs a little earlier in the third experiment, which was done largely in March, than in the first two, which fell roughly in January and February, respectively. The most notable feature of the transformation, however, is that the change of body color and the reproductive system in every case lags behind the change of color of antennae and tibiae and size of tibiae. These results are in striking agreement with those of table 2, in which only first offspring, resulting from high temperatures of different durations, are concerned. This lag of body color and reproductive system is referred to again later.

\section{Changes in the reproductive system Irom gamic to parthenogenetic}

The mean ratings of the reproductive systems in table 3 are, for the most part, determined from systems that were wholly gamic or wholly parthenogenetic. Among them, however, were 82 intermediate systems. 
Order of embryonic determination of the differential features of gamic etc.

99




In addition to these, 21 intermediate systems were obtained from other experiments in which high temperature gradually induced the production of parthenogenetic daughters. These intermediates do not fall into welldefined classes, since there are many ways of being intermediate. Nor can the intermediates be arranged precisely in the order of their nearness to one extreme or the other, because it is impossible to say which features are the most important in determining such relative rankings. A wholly satisfactory account of them would require a separate description of each individual system. Nevertheless, from the nature of the change that occurs earliest in successive lots of offspring, and from the frequency with which certain modifications appear, a general idea of the order of change, and very definite information about one or two features of it, may be gained.

-The first observed change in the gamic reproductive system, making it more like the parthenogenetic, was the reduction or loss of the colleterial glands and seminal receptacle. The earliest of the offspring to show any departure from the gamic type, during one of the transitions shown in table 3 , in a number of instances showed no other change than this. Moreover, in every system which showed any change whatever, reduction or loss of the colleterial glands and seminal receptacle was one of the changes. In systems which showed only a little more deviation from the gamic type, irregularity in the shape of the eggs was the commonest further modification. Next in order was the occurrence of more than two eggs in one or more of the ovarioles. In systems of about this same grade of intermediacy, the germarium was of slightly smaller relative size, and further reduction of it took place in all the later changes toward the parthenogenetic type. The number of eggs in each ovariole increased in irregular fashion, and the eggs gradually lost their opacity. In many systems, one or more ovarioles were of distinctly parthenogenetic type, others distinctly gamic, and progress toward the parthenogenetic was accomplished by an increase in the number of parthenogenetic ovarioles. Occasionally one or more ovarioles would contain each an opaquish gamic egg at the base, but parthenogenetically produced embryos beyond.

It is impossible, as stated previously, to arrange these changes in a given chronological order which is regularly followed. Especially the middle stages are mixed in their occurrence. One feature, however, is very definite: the first change to appear in successive offspring in any case is the reduction or loss of the colleterial glands and seminal receptacle. It is almost equally certain, also, that the next change is that the 
eggs become irregular in form. Besides this fixed order of events within the reproductive system, there is one equally definite relation between the changes in the reproductive system and changes in the secondary external characters. This one relation is that the reproductive system, in successive offspring, does not begin to change in any respect until the hind tibia has become as slender as that of a parthenogenetic female. Without exception, the 103 intermediate reproductive systems referred to above were all in animals whose hind tibiae were devoid of all traces of the swelling characteristic of gamic aphids.

\section{The time-of-determination theory of intermediacy}

Practically all previous work on intermediates designed to explain the mechanism of their production has been done on intersexes. Much of this work has been done by Goldschmidt, and an excellent review of the literature is given by him (Goldschmidt, 1927) in an article to which is appended a full bibliography. Goldschmidt's own theory of the development of intersexes is that they begin development in the manner characteristic of one sex, that a physiological change constituting a turning point occurs later, and that subsequent development is characteristic of the other sex. A structure which is determined before the turning point is reached will be like that of the former sex, one which is determined after the turning point will be like that of the latter sex. An intersex, according to this theory, is a time-mosaic of male parts and female parts whose embryonic determinations occur at different times in development.

There is probably as much reason, on a priori grounds, to apply the time-of-determination theory to other intermediates as to intersexes. In whatever situation it is applied, the conclusion to be drawn from it is that structures which are the earliest to be changed in successive offspring are the latest to be determined in development, while the latest to change in successive offspring are the first to be determined. The order of determination is the reverse of the order of modification in successive offspring. If this theory is applicable to intermediate aphids produced during a transition from the gamic to the parthenogenetic type, it means that the reproductive system and color of the body are determined before the color of antennae and size and color of the hind tibiae; and that within the reproductive system, the nature of the ovarioles and their contents is determined earlier than the colleterial glands and seminal receptacle.

Whether the time-of-determination theory is correct in any instance can never be proven by finding that all characters of the two types of 
individual change simultaneously. Nor is the theory confirmed by the discovery that certain characters change in earlier offspring than do the others. If intermediates that are near to the one extreme type always possess a given set of characteristics, and those near the other extreme type always have another given set of characteristics, these facts furnish no support to the time-of-determination hypothesis. What is needed to prove the theory is to discover (1) that when the intermediate condition is approached from one of the extremes the changes in successive individuals shall take place in a certain order, and (2) that when the intermediate condition is approached from the opposite extreme the same order of change shall prevail.

In the intermediate aphids described above, in which the intermediate form was reached from the gamic extreme, it was found that changes in the color of antennae and size and color of hind tibiae occurred in the earlier individuals, while body color and the reproductive system changed in later offspring; and that within the reproductive system, the colleterial glands and seminal receptacle changed before the ovarioles. If the intermediate form be reached from the opposite extreme, that is, by the conversion of parthenogenetic into gamic offspring, and if the time-theory is applicable to these aphids, the order of change should be the same. One should find the earlier offspring, during the period of transition, exhibiting changes in the antennae and hind tibiae; that is, their antennae should be darker, and their hind tibiae slightly swollen and darker, while all other features remained typical of parthenogenetic females. Only after such changes have appeared, should there be offspring with changed (yellowish instead of green) body color and a reproductive system leaning toward the gamic type. Within the reproductive system, the earliest offspring in such a series should show a change in the colleterial glands and seminal receptacle; that is, the system should possess colleterial glands and a seminal receptacle along with ovarioles of the parthenogenetic type. Only in later offspring should the ovarioles shrink in length, the germarium enlarge, and the eggs become opaque and remain unsegmented.

\section{Change from parthenogenetic to gamic}

It has keen fcund possible to induce the change demanded by the above considerations, that is, from parthenogenetic to gamic, under one set of conditions. Winged aphids whose prenatal development took place at low temperature were removed, within 24 hours after birth, to a tem- 
perature of $24^{\circ} \mathrm{C}$. This temperature should, within a period of about two weeks, cause all their offspring to be parthenogenetic, and it did in fact do so, as is shown below. Early in the reproductive period of these winged females, and before it was known precisely what effect the temperature had had, they were returned to a temperature of about $16^{\circ} \mathrm{C}$, where they were kept the remainder of their lives. Their offspring were reared in successive lots and, when mature, were individually judged with respect to the five differentiating characters of the two types of individuals. At the same time, as a further control, a lot of winged females from the same source, kept at $16^{\circ}$ until after reproduction had commenced, were then put at $24^{\circ}$ temperature for the remainder of their lives. The successive offspring of these two lots of parents, divided into (usually) 2-day groups at $24^{\circ}$ and 5-day groups at $16^{\circ}$, are given in table 4 .

Confirmation of the results previously obtained are found in the lower half of table 4. In the upper half, however, where the temperature was changed from high to low, there is a striking reversal of the order of change. The earliest offspring to show the effect of low temperature show it in their body color and reproductive system, and throughout the subsequent lots of offspring these two characters exhibit the greatest amount of change. The antennal and tibial changes lag behind.

Table 4. Offspring of winged aphids of two groups, one of which was first induced, by high temperature, to produce only parthenogenetic offspring and then was changed to $16^{\circ}$, the other having been kept at $16^{\circ}$ until reproduction started and then changed to $24^{\circ}$ temperature.

\begin{tabular}{c|c|c|c|c|c}
\hline \multirow{2}{*}{$\begin{array}{c}\text { Temperature } \\
\text { of Parents } \\
\text { in Degrees C }\end{array}$} & \multicolumn{5}{|c}{$\begin{array}{c}\text { Offspring of Winged Aphids Changed } \\
\text { from } 24^{\circ} \text { to } 16^{\circ}\end{array}$} \\
\cline { 2 - 6 } & $\begin{array}{c}\text { Color of } \\
\text { antenna }\end{array}$ & $\begin{array}{c}\text { Color of } \\
\text { body }\end{array}$ & $\begin{array}{c}\text { Size of } \\
\text { tibia }\end{array}$ & $\begin{array}{c}\text { Color of } \\
\text { tibia }\end{array}$ & $\begin{array}{c}\text { Reproductive } \\
\text { system }\end{array}$ \\
\hline & & & & & \\
24 & 4.00 & 4.00 & 4.00 & 4.00 & 4.00 \\
24 & 4.00 & 4.00 & 4.00 & 4.00 & 4.00 \\
16 & 4.00 & 4.00 & 4.00 & 4.00 & 4.00 \\
16 & 4.00 & 3.95 & 4.00 & 4.00 & 4.00 \\
16 & 4.00 & 3.15 & 4.00 & 4.00 & 3.28 \\
16 & 4.00 & 2.50 & 4.00 & 4.00 & 2.55 \\
16 & 4.00 & 1.96 & 4.00 & 4.00 & 1.91 \\
16 & 3.94 & 1.56 & 3.89 & 3.97 & 1.42 \\
16 & 3.60 & 1.12 & 3.46 & 3.62 & 1.20 \\
16 & 2.80 & 0.84 & 2.84 & 2.75 & 0.75
\end{tabular}




\begin{tabular}{c|c|c|c|c|c}
\hline \multirow{2}{*}{$\begin{array}{c}\text { Temperature } \\
\text { of Parents }\end{array}$} & \multicolumn{5}{|c|}{$\begin{array}{c}\text { Offspring of Winged Aphids Changed } \\
\text { from } \mathbf{1 6}^{0} \text { to } 24^{\circ}\end{array}$} \\
\cline { 2 - 6 } in Degrees C & $\begin{array}{c}\text { Color of } \\
\text { antenna }\end{array}$ & $\begin{array}{c}\text { Color of } \\
\text { body }\end{array}$ & $\begin{array}{c}\text { Size of } \\
\text { tibia }\end{array}$ & $\begin{array}{c}\text { Color of } \\
\text { tibia }\end{array}$ & $\begin{array}{c}\text { Reproductive } \\
\text { system }\end{array}$ \\
\hline & & & & & \\
16 & 1.25 & 0.15 & 0.31 & 0.48 & 0.00 \\
16 & 1.21 & 0.24 & 0.36 & 0.54 & 0.00 \\
24 & 1.31 & 0.13 & 0.27 & 0.50 & 0.00 \\
24 & 1.68 & 0.22 & 0.79 & 0.96 & 0.00 \\
24 & 1.80 & 0.41 & 1.26 & 1.45 & 0.00 \\
24 & 2.71 & 0.56 & 1.93 & 2.28 & 0.50 \\
24 & 3.22 & 0.87 & 2.89 & 3.14 & 0.95 \\
24 & 3.68 & 1.22 & 3.54 & 3.71 & 1.12 \\
& & & & &
\end{tabular}

With respect to the reproductive system, only 3 individuals in table 4 were intermediate. None of these had colleterial glands or seminal receptacle, and the ovarioles were variously intermediate with respect to shape, number and opacity of eggs and size of germarium.

\section{Significance of change from parthenogenetic to gamic}

The order of change in table 4 is not what the principle of time of determination would lead one to expect. In accordance with that theory, the change of body color and reproductive system should, in successive offspring, have lagged behind the change in antennal and tibial characters. Also, within the reproductive system, the colleterial glands and seminal receptacle should have been the first to change, in successive offspring, hence all offspring that were intermediate with respect to this system should have possessed these organs. ${ }^{*}$ Neither of these expectations is fulfilled.

\section{Possible explanations of the order of change}

At least three theories may be advanced to account for the nature of the intermediate aphids described above. Their respective advantages and the possibilities of testing their validity deserve attention.

1. Seleclive influence of temperature on development and birth of already determined types of embryos. It will be observed that the change from parthenogenetic to gamic offspring has been effected only in females in which the offspring had previously been changed from gamic to parthenogenetic. During that previous transition many intermediates were 
produced. These intermediates showed, on the average, relatively great modification of the antennae and hind tibiae, compared with a smaller change in the reproductive system. When the transition to parthenogenetic offspring appeared to be complete, and only parthenogenetic individuals were born, it is at least conceivable that there remained in the ovarioles a number of embryos destined to be intermediates of various grades, but that high temperature exercised a selective influence upon them and prevented these potentially intermediate embryos from completing their development and being born. Since the ovary of the parent consists of as many as ten ovarioles, any ovariole whose most advanced (posterior) embryo was to be parthenogenetic might, under the influence of high temperature, expel that embryo, and, if the following embryos were likewise destined to be parthenogenetic, a succession of parthenogenetic embryos might be brought to birth, while in any ovariole in which the posterior, most advanced embryo was to be an intermediate, high temperature could be supposed to stop further development and prevent birth. If, later, a winged female containing these intermediate and parthenogenetic embryos in different ovarioles were returned to low temperature, it is conceivable that the birth of the intermediates might thereby be facilitated, while birth of the parthenogenetic ones would be hindered. If the intermediates that were nearest to the parthenogenetic type were released first, the more nearly gamic ones later, the successive offspring would present a gradual return toward the gamic type. In this return, precisely the same kinds of intermediates would be born as were produced during the earlier transition from the gamic to the parthenogenetic type; that is, in them there would be relatively great deviations from the gamic type with respect to antennae and hind tibiae, and relatively small deviations from the gamic color and reproductive system. By the birth of successively more and more gamic-like intermediates of these sorts, there would be given the appearance of a return from the parthenogenetic to the gamic type of offspring in which the changes in the reproductive system and the color of the body would appear to take the lead, in successive offspring, while the antennal and tibial changes appeared to lag behind, just as the data in table 4 show they did.

This explanation would permit one to suppose that the nature of the intermediates produced during the transition from gamic to parthenogenetic offspring is dependent on the determination of the antennae, tibiae and parts of the reproductive system at different times in development, as Goldschmidt assumes in the case of intersexes. However, 
even if this selective action of temperature on development and birth could be shown to be the correct explanation of the intermediate aphids of table 4, this would not prove the correctness of the time-of-determination theory in explanation of the intermediates of table 3. Proof of the time-of-determination theory requires that the transition from one extreme to the other be made in both directions, and that the order in which the various structures are changed be the same in both. This condition is not met if a seletive action of temperature on birth takes place, since, under these circumstances, the apparent transition shown in table 4 is not a real transition at all, but only a remnant of the transition shown in table 3. Only one transition has taken place, on this theory, and the time-of-determination hypothesis can not be proven by transition in only one direction.

A suitable test of the explanation discussed in this section would be a transition from parthenogenetic to gamic offspring in a winged female whose early tendencies were to parthenogenetic daughters, provided intermediates appeared during the transition. Preferably there should be two or three generations of exclusively parthenogenetic daughters from winged mothers reared in ordinary conditions, to insure that no gamic nor intermediate embryos are being produced but withheld from birth. It may be possible to make this test, since it is not uncommon for winged aphids of this species to produce exclusively parthenogenetic young generation after generation during the summer. Attempts to make it with the strain of aphids being used for these experiments have so far been in vain. This is the strain whose response to temperature in the production of gamic and parthenogenetic individuals has been ascertained and published (Shull, 1930), and whose response to light and temperature in the production of wings has also been described (Shull, 1928, 1929). It has been reared in the laboratory since the spring of 1923, and its behavior is now so well known that a test of the possible selective action of temperature on birth would be more conclusive if made with the same strain than if made with a new parthenogenetic line. As stated, however, these attempts have failed because there has been no generation, since these experiments began, in which winged females produced only parthenogenetic offspring. Theoretically it should be possible to induce the production exclusively of parthenogenetic daughters by high temperature, but, as shown in previous work (Shull, 1928), winged individuals are not to be expected at such high temperatures. When temperatures low enough to permit winged daughters to appear are used, some of the off- 
spring of these winged daughters are gamic. This has been true in every generation since the desirability of making this test has been recognized; was true throughout the summer of 1929 at Woods Hole, Mass.; and reference to experiments performed in the summers of 1928 and 1927 show that in every instance in which winged females were bred, some of the offspring were gamic. In earlier summers, the experiments involved only wingless females. Mention is made here only of summer experiments, since, at the lower temperatures of winter, gamic daughters appear, not as occasional, but as the regular progeny of winged mothers. Whether, therefore, the selective action of temperature on the birth of different kinds of embryos can be used to explain the intermediates of table 4 must probably remain unsettled until the response of some other parthenogenetic line to temperature can be fully ascertained, and the experiments outlined above can be performed.

2. Differential influence of temperature on time of determination of various structures. This explanation presupposes that the time-of-determination theory is applicable to the intermediate aphids; that is, that antennae and hind tibiae change early in a series of successive offspring because their nature is fixed late in development, while the body color and reproductive system change late in such a series of offspring because their nature is decided early in development. All that this explanation needs to account for, therefore, is the reversed order of change in table 4, as compared with table 3 . The high temperature applied during the transition represented in table 3 , and the low temperature that caused the change shown in table 4, certainly had different effects on the general rate of development. If, now, the rates of development of the several structures are modified to different degrees, it might follow that the times of determination are shifted to relatively different points in development. To explain the different orders of change shown in tables 3 and 4 , it would be necessary to suppose that, at high temperature (table 3 ) the body color and reproductive system were decided before antennae and tibiae, while at low temperature (table 4) antennae and tibiae were determined before body color and reproductive system.

Whether this differential effect of temperature on time of determination is a priori probable, is a matter of opinion. It is unfortunate that the agent used to convert one type of offspring into the other must be one which modifies the rate of development. The only other factor known to effect this conversion is light (Shull, 1930), and it is much less potent than temperature. Continuous light favors parthenogenetic 
offspring, alternating light and darkness favor gamic offspring, provided the prevailing temperatures are not decisively favorable to the one or the other. However, in none of the experiments in which light changed the nature of the offspring have any undoubted intermediates been produced. Attempts are still being made to btain intermediates in this way, but there seems to be little likelihood of success.

3. Nature of intermediate the same for any degree of intermediacy regardless of direction of approach. The reversal of the order of change of different structures in tables 3 and 4 would be a necessary consequence if each grade of intermediate possesses certain characteristics, and if the several structures change at different rates as the degree of intermediacy changes. Thus, it might be supposed that an intermediate that is very near the gamic extreme would have antennae slightly paler and hind tibiae slightly paler and thinner than typical gamic females, and a strictly gamic reproductive system, regardless of whether that intermediate has been produced by slight modification of a gamic female toward the parthenogenetic, or by a nearly complete conversion of a parthenogenetic female into a gamic one. An intermediate that is near the parthenogenetic extreme might have in every case a yellowish green body color, a reproductive system without colleterial glands or seminal receptacles and with ovarioles of mixed types, together with antennae and hind tibiae strictly of the parthenogenetic type. It may be supposed that these would be its characteristics, irrespective of whether the intermediate condition had been produced by long application of high temperature to a winged female previously producing gamic daughters, or by a briefer application of low temperature to a winged female previously producing parthenogenetic offspring. In like manner, it could be assumed that an intermediate of medium grade would have antennae and hind tibiae like those of parthenogenetic females, but a reproductive system like that of a gamic female, no matter from which extreme the intermediate condition had been reached.

The degree of intermediacy might be dependent upon the stage at which some physiological process had arrived at some critical time. Perhaps it would depend on the quantity of some substance present at that time. If all of the differentiating characters responded equally to changes in the quantity of this substance, or the "level" of this physiological process, the question of order of determination would not arise; all structures would appear to be determined at the same time, or over the same period. Since, however, dark and swollen tibiae and dark an- 
tennae respond to a slight increase (let us say) of this substance by becoming paler, or paler and slenderer, while body color does not become greener nor the colleterial glands disappear until a greater increase (be it assumed) of this substance has taken place, there arises a situation in which a difference in the time of determination of these structures may be suspected, although such a difference were non-existent.

This explanation would deny any importance to differences in the time of embryonic determination of different parts. There might be such differences, but they would not determine the composition of the intermediate individuals.

Since Goldschmidt's theory of the intersexes is so far the only well-defined theory relating to the mechanism of production of intermediate animals, it is of interest to refer again briefly here to the relation of the above three possible explanations to the time-of-determination hypothesis. The first explanation permits one to assume that the time of determination decides the constituent parts of an intermediate, but argues neither for nor against the correctness of that assumption. The second explanation directly recognizes the time-of-determination theory, and is built upon it. The third explanation excludes time of determination as of any influence upon the nature of the intermediate forms. There is at present no very good reason for holding, and certainly no reason for expressing, an opinion favoring one or another of these several explanations. The first two appear still to have some chance of being rendered either probable or improbable by further experimental evidence, while the third would be made highly probable if the first two were disproven.

\section{Summary}

Gamic and parthenogenetic females of the aphid species Macrosiphum solanifolii differ in the color of the antennae, color and size and sensoria of the posterior tibiae, color of body, and several features of the reproductive system.

When the offspring of winged females are gradually changed from gamic to parthenogenetic females, these differential features do not all change at the same time nor at the same rate. The earliest offspring to show any change, during such a period of transformation, show the change in the antennae and hind tibiae. Only later offspring show changes in the body color and reproductive system. Within the reproductive system 
the earliest change to take place in successive offspring is the loss of the colleterial glands and seminal receptacle; later offspring show various modifications of the ovarioles.

If the order of change in successive offspring is determined by the times in embryonic development at which the fate of the various structures is decided, as has been postulated for intersexes, the order of embryonic determinations must be the reverse of the order of change in successive offspring. Consequently, if the transformation can be effected in the opposite direction, that is, from parthenogenetic to gamic, the same order of determination and the same order of change in successive offspring should prevail, though-each individual feature should be altered in the opposite direction.

Contrary to this expectation, when winged females, whose offspring have been changed from gamic to parthenogenetic by high temperature, are then returned to low temperature so that their offspring gradually change back to the gamic type, this latter change takes place in a different order. The early offspring show changes in the body color and reproductive system, while changes in the antennae and hind tibiae begin later. What evidence there is, relative to the parts of the reproductive system, indicates that the colleterial glands and seminal receptacle are not changed before the ovarioles, in the succession of offspring.

Three possible explanations of this reversed order of change are discussed. (1) It may be due to a selective action of low temperature, favoring the development and birth of embryos more like the gamic type. The validity of this explanation apparently can not be tested until control of the type of female has been attained in some other strain of aphids. (2) Temperature may have different effects on the rate of development of different structures, and so shift their moments of determination to opposite sides of the turning point in development. Attempts to discover some other agent than temperature which will produce intermediate females have not succeeded. (3) The characteristics of intermediates may depend upon their degree of intermediacy, and be the same for any grade regardless of whether that grade has been reached from the gamic extreme or the parthenogenetic extreme.

The first of these explanations permits, but does not necessarily favor, the assumption that time of determination of structures decides the composition of intermediates. The second explanation assumes that time of determination is the deciding factor. The third explanation is opposed to the time-of-determination hypothesis. 


\section{Bibliography}

Goldschmidt, R., 1927. Die zygotischen sexuellen Zwischenstufen und die Theorie der Geschlechtsbestimmung. Ergeb. d. Biol. 2 : 554-684.

Shull, A. F., 1928. Duration of light and the wings of the aphid Macrosiphum solanifolii. Roux Arch. d. Entwickl. d. Org., 113 : 210-239.

-, 1929. The effect of intensity and duration of light and of duration of darkness, partly modified by temperature, upon wing-production in aphids. Roux Arch. d. Entwickl. d. Org., 115 : 825:851.

-, 1930. Control of gamic and parthenogenetic reproduction in winged aphids by temperature and light. Zeitschr. ind. Abst. Vererb., 55 : 108-126. 